\title{
Hyperpolarized Helium 3
}

National Cancer Institute

\section{Source}

National Cancer Institute. Hyperpolarized Helium 3. NCI Thesaurus. Code C128033.

A contrast agent composed of hyperpolarized helium $\mathrm{He} 3$ gas $(\mathrm{HP} 3 \mathrm{He})$, with potential usage in diagnostic nuclear magnetic resonance (NMR)-based imaging (MRI). Upon inhalation, the hyperpolarized helium $\mathrm{He} 3$ gas is distributed throughout the lungs. MRI, immediately following HP3He administration, allows for the visualization of lung structures based on the distribution pattern of the gas. This may aid in the diagnosis of certain lung abnormalities. Hyperpolarization of $\mathrm{He} 3$ enhances NMR signals and thus improves imaging and assessment of lung function. 